\title{
The interpretation of syntactically unconstrained anaphors in Turkish heritage speakers
}

\author{
Martina Gračanin-Yuksek ${ }^{1}$, Sol Lago ${ }^{2}$, Duygu Fatma Şafak ${ }^{3}$, Orhan Demir ${ }^{1}$ and Bilal \\ $\mathrm{K}_{1 \mathrm{rk} 1 \mathrm{c1}}{ }^{1}$ \\ ${ }^{1}$ Middle East Technical University, Ankara, Turkey \\ ${ }^{2}$ Potsdam Research Institute for Multilingualism, Potsdam, Germany \\ ${ }^{3}$ University of Braunschweig, Braunschweig, Germany
}

\begin{abstract}
Previous work has shown that heritage grammars are often simplified compared to their monolingual counterparts, especially in domains in which the societally-dominant language makes fewer distinctions than the heritage language. We investigated whether linguistic simplification extended to the anaphoric system of Turkish heritage speakers living in Germany. Whereas the Turkish monolingual grammar features a three-way distinction between reflexives (kendi), pronouns $(o)$, and syntactically-unconstrained anaphors (kendisi), German only distinguishes between two categories, pronouns and reflexives. We examined whether heritage speakers simplified the Turkish anaphor system by assimilating the syntactically unconstrained anaphor kendisi to either of the two categories attested in the societally-dominant language, German. Speakers' sensitivity to grammatical distinctions in comprehension was assessed using an offline antecedent selection task and an online self-paced reading task. Our results showed that heritage speakers retain the three-way anaphoric distinctions of the monolingual grammar but there were also differences between the results of the offline and the online tasks. We suggest that processing paradigms are a useful complement to judgment tasks when studying how heritage speakers use grammatical distinctions involving optionality, as online measures can reveal distinctions that are allowed, even if dispreferred by comprehenders.
\end{abstract}

Keywords: heritage language, sentence processing, anaphors, Turkish, German.

\section{Introduction}

Heritage languages are particularly interesting because they are simultaneously privileged and vulnerable in speakers' mind. A heritage language is privileged as the speakers' native language, different from other languages learned later in life (Schmid and Köpke, 2007). However, the fact that it is not the dominant language in the society where speakers live renders it vulnerable and prone to change (Benmamoun et al., 2013; Kupisch and Rothman, 2016; Scontras et al., 2015). Here we focus on one important trend of change in heritage grammars, linguistic simplification, and we examine whether it affects the anaphoric system of heritage Turkish speakers living in Germany. The heritage Turkish anaphoric system holds promise for investigating linguistic simplification because the distinctions 
made by the monolingual Turkish grammar are more complex than those made by the German grammar: while German only has pronouns and local reflexives, Turkish also has reflexives that allow long-distance and discourse binding. Our research question is whether heritage speakers reduce the grammatical categories of Turkish anaphors or whether these categories are preserved, showing resiliency to heritage language conditions.

The observation that heritage languages often simplify grammatical categories present in their monolingual counterparts is common in previous work (e.g., Putnam and Arnbjörnsdóttir, 2015). Typically, simplification results in the heritage language converging with the dominant language model, usually the national language of the country of residence (Aalberse and Muysken, 2011). For example, Russian heritage speakers in the United States collapse the six-case system of Russian into a simpler nominative-accusative contrast, the two cases most commonly attested in English and other languages with reduced case systems (Leisiö, 2001; Polinsky, 2006; Zemskaja, 2001). A similar observation concerns inflectional markers, which are often omitted by heritage speakers of morphologically rich languages such as Russian, Lithuanian, Polish and Palestinian, especially when their dominant language has poor inflectional morphology (Albirini et al., 2013; Polinsky, 1997). Further, simplification is observed at the level of semantics, in phenomena like quantifier scope ambiguity. Heritage speakers of English, which allows both surface and inverse scope in doubly quantified sentences, have been reported to lack inverse scope under heritage language conditions (Ronai, 2017; Scontras et al., 2017; Tsai et al., 2014). Finally, simplification can affect optionality in the use of syntactic structures: for instance, Irizarri van Suchtelen (2012) showed that whereas psychological verbs in Spanish allow experiencers to be encoded by either a dative argument or a subject (with monolinguals preferring the dative option), Spanish heritage speakers in the Netherlands strongly prefer subject experiencers, the only option available in Dutch.

In order to appropriately describe linguistic simplification, a definition of complexity is needed. Here we adopt an explicit metric of complexity (Hawkins, 1994; 2004), which integrates theoretical proposals (Berwick, 1985; Miller and Chomsky, 1963) with psycholinguistic considerations. According to this metric, grammatical complexity depends on: (i) the number of linguistic forms (e.g., phonemes, morphemes, words) needed to construct an utterance: the more forms, the more complex the grammar; (ii) the number of syntactic and semantic properties assigned to these forms: the more properties per form, the more complex the grammar; (iii) the size of the domain in which these properties are assigned: the larger the domain, the more complex the grammar.

Hawkins suggests three general principles that reduce complexity from the comprehension perspective: Minimize Domains, Minimize Forms, and Maximize online processing. Minimize Domains is particularly relevant for the current study, because it proposes that in the computation of a syntactic dependency (such as identifying the antecedent for an anaphor) the parser prefers the domain of the dependency to be as minimal as possible. Specifically, Hawkins (2004: 31) proposes that "the parser prefers to minimize the connected sequences of linguistic forms and their conventionally associated syntactic and semantic properties in which relations of combination and/or dependency are processed". For example, given an antecedent-anaphor dependency (e.g., Mary $y_{\mathrm{i}}$...herself $f_{\mathrm{i}}$ ), utterances that minimize the number of words in the domain containing these elements,

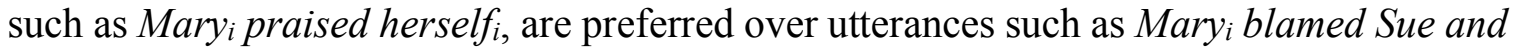
praised Bill and herself $f_{i}$, which contain a higher number of intervening words and thus 
additional semantic and syntactic properties to be processed. Similarly, in order to infer the subcategorization frame of a ditransitive verb like give, utterances that make the identity of the arguments available sooner will be preferred over alternative utterances. For example, in an utterance like Mary gave [PP to Bill] [NP the book that she had been searching for since last Christmas] the arguments of the verb (the PP and the NP, signaled by the preposition to and the determiner the respectively) can be identified after parsing only three words after the verb. Consequently, such an utterance is simpler and thus preferred over the utterance Mary gave [NP the book that she had been searching for since last Christmas] [PP to Bill], where 12 words need to be parsed before the arguments of the verb are identified.

The ultimate reason why simpler structures are preferred is that they are processed more easily and/or efficiently. Thus, the preference for minimal domains could be linked to the limited nature of speakers' working memory, as shorter dependencies should reduce memory load (Futrell et al., 2015; Gibson, 2000; Lewis and Vasishth, 2005). The relevance of this claim for heritage languages is that more complex and thus harder to process grammatical distinctions are more likely to be simplified, especially in cases where the societally-dominant language lacks analogous distinctions. The anaphoric systems of Turkish and German offer an interesting scenario to study simplification because they differ in the number and nature of their grammatical categories. Below, we outline the behavior of these systems before turning to previous research on coreference in heritage languages.

\section{Anaphors in German and Turkish}

We describe the behavior of Turkish and German third person singular anaphors when they function as grammatical objects, which is the position they occupy in the materials of the current study. The German anaphor system only distinguishes between pronouns and local reflexives (Lee-Schoenfeld, 2004; Reuland, 2006; Ruigendijk et al., 2010). The reflexive form sich 'himself/herself' is subject to Principle A of the Binding theory (Chomsky, 1981) and needs to be bound by an antecedent within its local domain (henceforth, a local antecedent). By contrast, pronoun forms such as $i h n / i h r$ 'him/her', are subject to Principle $\mathrm{B}$ and do not allow co-reference with local antecedents. This holds both when anaphors are objects of the matrix clause and when they are objects in an embedded clause, as illustrated in $(1-2){ }^{1}$

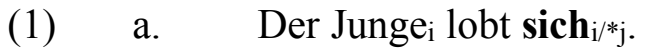

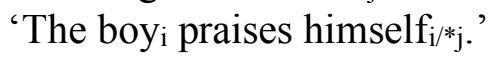

b. Hans $\mathrm{j}_{\mathrm{j}}$ weiß, dass der Junge $\boldsymbol{~ s i c h ~}_{\mathrm{i} / *_{\mathrm{j}}}$ lobt.

'Hans knows that the boy $_{\mathrm{i}}$ praises himself $\mathrm{f}_{\mathrm{i} / \mathrm{j} \text {.' }}$,

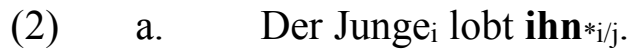

'The boyi praises him $*_{\mathrm{i} / \mathrm{j}}$ ',

b. Hans $\mathrm{j}_{\mathrm{j}}$ weiß, dass der Junge $\mathrm{ihn}_{\mathrm{i}} \mathrm{i}_{\mathrm{j}}$ lobt.

'Hans $\mathrm{j}_{\mathrm{j}}$ knows that the boy $\mathrm{y}_{\mathrm{i}}$ praises him $*_{\mathrm{i} j \mathrm{j}}$.' 
Turkish is similar to German, in that it also has a pronoun form $o$ 'he/she/it' and a reflexive form kendi 'self'. The pronoun $o$ is subject to Principle B and cannot refer to local antecedents (Göksel and Kerslake, 2005; Kornfilt, 1997; Rudnev, 2008; Underhill, 1976). The reflexive kendi, on the other hand, refers to local antecedents and is subject to Principle A of the Binding Theory (Enç, 1989; George and Kornfilt, 1981; Göksel and Kerslake, 2005; Kornfilt, 2001; Rudnev, 2008). Note, however, that the literature on Turkish also contains reports according to which, when kendi is in the third person singular, it can additionally accept an antecedent in a higher clause (henceforth, a long-distance antecedent; Cem Değer, 1996; Meral, 2010, 2013; Özbek and Kahraman, 2016; Sezer, 1980, 1991; Yakut, 2015). Therefore, kendi functions mainly as a local anaphor, except in the third person singular, where it additionally accepts long-distance readings.

Crucially, Turkish differs from German in that it features a second type of reflexive, the anaphor kendisi, which is syntactically unconstrained and can corefer with local and long-distance antecedents, as well as antecedents not mentioned within the sentence where it appears (henceforth, an extra-sentential antecedent; Enç, 1989; Gürel, 2002, 2006; Kornfilt, 1997). Examples of the three anaphors are provided in (3-5); parentheses around the subscript $i$ in (4) allude to the fact that some syntactic reports allow long-distance coreference for kendi. Note that the anaphors are case-marked, but not gender-marked, as Turkish lacks grammatical gender.

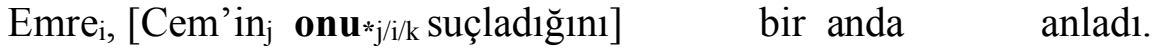

$$
\begin{aligned}
& \text { Emre Cem.GeN } \text { O.ACC }_{\text {blame. }} \text {.3SG.POSS.ACC one moment.LOC understood } \\
& \text { 'Emre } e_{i} \text { realized right away that } \mathrm{Cem}_{\mathrm{j}} \text { is blaming him/her }{ }^{*}{ }_{\mathrm{j} / \mathrm{k}} \mathrm{k} \text {.' }
\end{aligned}
$$

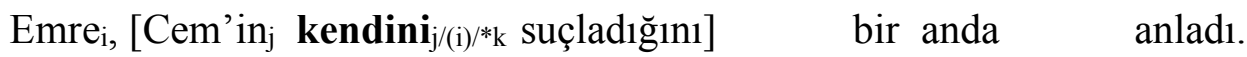

Emre Cem.GEN kendi.ACC blame.N.3SG.POSS.ACC one moment.LOC understood

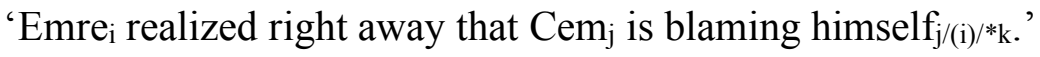

Emre $_{i}$, [Cem'in ${ }_{j}$ kendisini $_{j} i_{i k}$ suçladığını bir anda anladı.

Emre Cem.Gen kendisi.ACC blame.N.3SG.POSS.ACC one moment.LOC understood 'Emre $e_{i}$ realized right away that $\mathrm{Cem}_{\mathrm{j}}$ is blaming himself/herself/him/her $\mathrm{j}_{\mathrm{j} i \mathrm{k} .}$.'

The examples above illustrate that the Turkish and German anaphoric systems differ in that German contains two forms, but Turkish contains three. At first sight, the presence versus absence of a single lexical form, whose interpretation does not require any additional syntactic constraints, might seem inconsequential. Nevertheless, this form increases syntactic complexity from the point of view of processing load, specifically in light of the Minimize Domains principle proposed by Hawkins (2004). This is because in German, if an anaphor is bound by an antecedent contained within its minimal domain, then it cannot be bound by an antecedent outside this domain (and vice versa). Due to this complementary distribution, when the German parser encounters a reflexive (or a pronoun), it "knows" that the antecedent cannot be outside the local domain (or inside the local domain for pronouns), thus reducing the number of referential possibilities and reducing processing load. But in Turkish, when the parser encounters the syntactically unconstrained kendisi, the search for the antecedent cannot disregard the local domain (within which antecedents of the reflexive kendi are found), nor can it disregard the non- 
local domain (within which antecedents of the pronoun $o$ are found). Thus, since kendisi is not in complementary distribution with the other two forms (kendi and o), and it is syntactically unconstrained, the search for an antecedent always proceeds in three different domains, creating a larger search space and increasing processing load, resulting in a more complex anaphoric system.

Thus, if the Turkish anaphoric system undergoes simplification under heritage language conditions, especially given the properties of the societally-dominant German, we expect it to become more similar to the German system. This change should impact the behavior of the syntactically unconstrained reflexive kendisi by eliminating some of the domains in which the search for its antecedent proceeds. Specifically, given the parser's preference for smaller domains, as proposed by Hawkins' principle Minimize Domains, we expect the reference of kendisi to be restricted to local antecedents (in the case of full simplification) or to local and long-distance antecedents (in the case of partial simplification). Further, to the extent that Turkish kendi 'self' is a local anaphor like German sich 'self', it should preserve a local reading. However, given the possibility of long-distance reference for kendi (Cem Değer, 1996; Meral, 2010, 2013; Özbek and Kahraman, 2016; Sezer, 1980, 1991; Yakut, 2015), simplification might involve the loss of this reading, turning kendi into a local anaphor. By contrast, since both in German and in Turkish pronominal forms exhibit parallel behavior - both are constrained by Principle $\mathrm{B}$ - we expect simplification not to affect the interpretation of $o$ in heritage Turkish.

Finally, it should be noted that changes in the behavior of kendisi in the Turkish heritage grammar are not predicted by accounts that do not assume simplification to be driven by processing limitations. For example, some previous work has suggested that heritage languages show signs of attrition only for elements that are in competition with corresponding elements in the societally-dominant language (Ben-Rafael, 2004; Gürel, 2004; Gürel and Yilmaz, 2011; Köpke, 2002; 2007; Paradis, 1993, 2007). According to this work, Turkish heritage speakers should not assimilate kendisi to kendi or to $o$ given that German has no syntactically unconstrained anaphor that would be in competition with kendisi.

\section{Anaphors in heritage grammars}

Previous studies have often found differences between heritage and monolingual anaphor systems. But so far, studies on heritage speakers have examined their performance in either production tasks or offline (i.e., untimed) comprehension tasks. For example, a production study by Putnam and Arnbjörnsdóttir (2015) investigated the long-distance binding of the anaphor sig 'self' in heritage Icelandic in North America. They reported that in the heritage grammar, sig no longer allowed long-distance binding and instead required an antecedent within the local domain, similarly to English reflexives. The authors attributed this behavior to the loss of another feature: the morphophonemic reflex of the subjunctive mood, which is necessary for the long-distance licensing of sig.

In a similar vein, Kim and colleagues (2009) investigated the binding interpretations of local and long-distance anaphors in English-dominant heritage speakers of Korean. Korean has three reflexives: casin, caki, and caki-casin. Whereas casin shows no preference, caki-casin prefers local antecedents and caki prefers long-distance ones. The results of an untimed antecedent selection task showed that heritage speakers maintained 
the distinction between local and long-distance anaphors but showed a preference towards local antecedents. Specifically, they recognized the ambiguity of casin and caki but preferred local antecedents to a greater degree than monolinguals. A local preference was also observed with caki-casin, although long-distance interpretations were rejected less often than by monolinguals. A later study investigated the binding possibilities of caki in second-generation immigrant speakers of Korean in the United States (Kim et al., 2010). Again, heritage speakers dispreferred long-distance antecedents for caki more often than Korean monolinguals and Korean adult learners of English, a result that the authors attributed to their early exposure to English, in which reflexives are locally bound.

With regard to the anaphoric system of Turkish, this issue was first examined by Gürel $(2002,2004)$ in a population of first-generation Turkish immigrants in North America. Gürel tested the referential possibilities of anaphors $o$, kendisi and the null pro when they functioned as grammatical subjects in an embedded clause. In this position, since there is no local antecedent, kendisi may be long-distance bound by the subject of the matrix clause or it may pick an extra-sentential antecedent, but $o$ resists long-distance binding and needs an extra-sentential antecedent, i.e., it must be disjoint in reference from the matrix subject.

First-generation Turkish immigrants performed offline antecedent selection and truth-value judgment tasks. In the selection task, sentences containing anaphors were presented in isolation and participants needed to select an appropriate antecedent. In the truth-value judgment task, the same sentences were preceded by a story (either consistent or inconsistent with the syntactic constraint of the anaphor) and participants had to decide whether the experimental sentence was true or false given the context. Across tasks, Turkish immigrants clearly preferred intra-sentential antecedents. In the selection task, they treated kendisi as less ambiguous than the monolinguals, showing a strong preference for the matrix subject antecedent ( $81 \%$ vs. $36 \%$ in the monolingual group). They also allowed $o$ to co-refer with the matrix subject: in 15\% of the trials they found $o$ ambiguous between the bound and disjoint reading, while in $1 \%$ of the trials they only accepted the bound interpretation. For comparison, monolinguals treated $o$ as ambiguous in 5\% of the trials and preferred only the bound interpretation in $1 \%$ of the trials. These results led to the conclusion that the referential system of the first-generation immigrants had undergone restructuring consistent with their dominant English system.

It is informative to compare these results with a later study by Gürel and Yilmaz (2011), which examined both first-generation Turkish speakers in North America and the Netherlands and second-generation Turkish heritage speakers of Dutch in the Netherlands. Their results showed that first-generation immigrants preserved the referential ambiguity of kendisi to a lesser extent than the monolingual group, and they were more likely to interpret $o$ as co-referential with the matrix subject, an option illicit in the monolingual grammar. Crucially, the heritage group also showed less evidence of ambiguity for kendisi, and an even stronger matrix subject preference for $o$, suggesting a consolidation of the transformed preferences of the first-generation group.

Overall, previous studies suggest that heritage speakers are sensitive to the anaphoric distinctions present in the monolingual grammar, but that their anaphor system undergoes changes when they live in an environment with a different dominant language. These changes show a trend towards the simplification of the heritage grammar, with a preference towards local binding for reflexives. But so far, previous work has mostly 
examined speakers' interpretative preferences using offline tasks, often combined with explicit judgments. Therefore, it is less known how heritage speakers deploy the grammatical options of their anaphor system using methodologies that measure how the processing changes as the sentence unfolds. The current study aimed to address this gap.

\section{The present study}

We examine whether Turkish heritage speakers living in Germany simplify their anaphor system by assimilating it to the syntactic categories of the societally-dominant language, German, or whether they preserve the distinctions even under heritage language conditions. Our study builds on a previous study on the processing of Turkish anaphors, which examined how Turkish monolinguals interpreted kendi, kendisi, and $o$ in an offline antecedent selection task and also during reading comprehension, using a self-paced reading task (Gračanin-Yuksek et al., 2017).

Importantly, the behavior of monolinguals was found to depend on the nature of the task. In the antecedent selection task, exemplified in (6) with kendisi, the anaphors functioned as embedded objects in isolated sentences. The judgments of Turkish monolinguals showed a two-way distinction: $o$ resisted local antecedents $(\mathrm{Cem})$ but accepted long-distance and extra-sentential antecedents (Emre and someone else respectively). On the other hand, kendi and kendisi were treated similarly and were allowed to co-refer with local and long-distance antecedents, but not with extra-sentential antecedents.

$$
\begin{aligned}
& \text { Emre, Cem'in kendisini suçladığını bir anda anladı. } \\
& \text { Emre Cem.Gen himself/him.ACC blame.N.3SG.POSS.ACC one moment-in realized } \\
& \text { 'Emre realized right away that Cem is blaming himself/him.' }
\end{aligned}
$$

Suçlanan kişi kimdir? (Lütfen olası tüm uygun yanıtları işaretleyiniz.)

'Who is the person being blamed? (Please, select all applicable options.)'
(a) Emre
(b) Cem
'Emre'
'Cem'
(c) Başka biri
'Someone else'

The availability of long-distance reference for kendi was consistent with previous syntactic proposals that allow this behavior in the third person singular form of the anaphor (Cem Değer, 1996; Meral, 2010, 2013; Yakut, 2015). However, judgment preferences with kendisi were unexpected: given its syntactically-unconstrained nature, coreference with an extra-sentential antecedent should have been observed. The authors attributed its absence to a previously proposed pragmatic constraint, according to which kendisi "must pick out an individual that is already in the domain of discourse and cannot be used to introduce an individual into the domain of discourse" (Enç, 1983: 85). Thus, the lack of extra-sentential antecedent choices for kendisi was attributed to the set-up of the antecedent selection task, which did not identify an extra-sentential referent within the stimuli and only named it as 'someone else' in the response options.

To exclude a possible effect of the selection task and to obtain an online measure of monolinguals' behavior, the authors conducted a self-paced reading study, in which the 
target sentences were preceded by biasing contexts that favored local, long-distance, or extra-sentential antecedents. As predicted, participants' reading times after the anaphors showed evidence of a three-way distinction: monolinguals showed reading disruptions with $o$ in local biasing contexts, but no difficulties in contexts with long-distance or extrasentential biases. By contrast, kendi was processed without difficulty in contexts with local and long-distance biases, but elicited reading disruptions in extra-sentential biasing contexts. Finally, speakers showed no processing difficulties for kendisi, which was read similarly quickly in the three contexts, suggesting that monolinguals were able to effortlessly resolve it towards any of the antecedents favored by the context. The absence of processing disruptions with kendisi, but not with kendi and $o$, was taken as evidence of the syntactically-unconstrained nature of kendisi in the monolingual grammar.

The present study examines the anaphoric interpretations of heritage Turkish speakers, using the materials of Gračanin-Yuksek and colleagues (2017) in both an offline antecedent selection task and an online self-paced reading task. We asked whether Turkish heritage speakers living in Germany retained the distinctions of the Turkish monolingual grammar or whether they simplified their anaphoric system to the categories present in the German grammar. We predicted that linguistic simplification should occur according to the principles outlined by Hawkins (1994; 2004), thus mainly affecting the syntactically unconstrained anaphor kendisi, which is also unattested in German. More specifically, given the increased complexity of computing dependencies over larger licensing domains, as well as the empirical patterns observed in previous work, we predicted heritage speakers to favor local antecedents for kendisi. This should potentially also result in a preference towards local reference for kendi, thus eliminating the acceptability of long-distance binding previously observed in monolingual speakers (Gračanin-Yuksek et al., 2017; Ozbek and Kahraman, 2016). Finally, the anaphor $o$ was not predicted to undergo any changes in the heritage grammar given the existence of a corresponding form in German.

All our participants lived in Germany, used German proficiently and had learned it during childhood. Therefore, although they had acquired Turkish from birth, it was their heritage language because it was "a language spoken at home or otherwise readily available to young children and crucially [...] not a dominant language of the larger (national) society" (Rothman, 2009: 156). Our study did not attempt to separate the potential roles of attrition and incomplete acquisition, as sometimes done by previous work on bilinguals. Incomplete acquisition presupposes that some aspects of language are not acquired, despite being available in the input. But based on previous literature, it is likely that any changes found in heritage speakers also affected the first generation due to attrition (Gürel, 2002, 2004; Gürel and Y1lmaz, 2011; Montrul and Sanchez-Walker, 2013; Pires and Rothman, 2009; Rothman, 2007; Sorace, 2004). Since we did not collect information about the input that our participants were exposed to, our study does not address whether the properties of their heritage language should be attributed to incomplete acquisition or to attrition. Finally, our experiments did not seek to compare heritage with monolingual speakers. In line with recent work, which argues that monolingual grammar should not be taken as a golden model against which heritage grammar should be evaluated (Kupisch and Rothman, 2016; Rothman and Treffers-Daller, 2014), we refrained from comparing heritage speakers with monolinguals, who acquired their language in a different context and under different circumstances, and who had more formal literacy training. Instead, we sought to study 
heritage speakers in their own right, asking how they deployed their grammatical knowledge during reading.

\section{Experiment 1}

Experiment 1 used an antecedent choice task to examine heritage speakers' untimed preferences. Participants were presented with isolated sentences that featured the anaphors $k e n d i$, kendisi or $o$ as grammatical objects in embedded clauses and they were asked to identify all possible antecedents.

\section{Participants}

Heritage speakers were recruited from Turkish-speaking communities in Germany. After the exclusion of one participant with low filler accuracy, twenty-nine participants were entered in the analysis (mean age $=25$ years, age range $=18-46,20$ females, 27 righthanded). All heritage speakers had acquired Turkish from birth and German before puberty, with an early age of acquisition of German ( mean $=2.74$ years; $\mathrm{SD}=2.89$ years). All speakers had a university or tertiary degree and three had also a postgraduate degree. The majority of the group reported use of both Turkish and German, with the exception of three speakers, who reported using Turkish less than $10 \%$ of the time per week, and one speaker who reported using German less than $10 \%$ of the time per week. However, these speakers reported high proficiency levels in the respective languages and performed accurately on the fillers, and therefore they were kept in the analysis.

Participants' language proficiency was assessed via self-ratings, which have been found to show good correspondence to formal language tests (Blanche and Merino, 1989; Marian et al., 2007; Ross, 1998). Participants rated their Turkish and German proficiency in each of the four skills (speaking, listening, reading, and writing) using a scale from 110. These ratings were then averaged to get an overall measure of their language proficiency. The average Turkish proficiency was $89 \%(\mathrm{SD}=10 \%)$ and the average German proficiency was $96 \%(\mathrm{SD}=7 \%)$. Participants' reading proficiency in Turkish aligned closely with their overall proficiency (mean $=88 \%$; SD $=14 \%$ ). This was important because the experiment relied on participants' reading skills. In this and following experiments, participants provided informed consent and all procedures were in accordance with the Declaration of Helsinki.

\section{Materials and procedure}

Materials consisted of nine experimental sentences and nine filler items. In the experimental sentences, the anaphors of interest (kendi, kendisi, and $o$ ) appeared as the direct objects of the verb, as shown in (7). The verb in the embedded clause was carefully selected: it had to be a transitive verb capable of taking two animate arguments (e.g., blame, praise, harm) and it had to be similarly felicitous with reflexive and non-reflexive interpretations when embedded under the matrix verb (realize, learn, notice). Based on the judgments of two native Turkish speakers, only nine verbs met these restrictions, thus restricting the number of possible items. This is a limitation of the current experiment, 
which differed from previous judgment studies with a larger number of items (e.g., Gürel, 2002).

Each experimental sentence was followed by a question probing for the interpretation of the critical anaphor, and three response options, corresponding to the longdistance antecedent (7a), the local antecedent (7b), and an extra-sentential antecedent (7c). Participants were asked to select all possible antecedents. All experimental materials, as well as data for this and following experiments, are available at the Open Science Framework website (https://osf.io/).

Hamza, Ahmet'in kendini/kendisini/onu övdüğünü olayca fark etti.

Hamza Ahmet.Gen kendi/kendisi/o.ACC praise.N.3SG.POSS.ACC easily realized.

'Hamza easily realized that Ahmet is blaming himself/him.'

Övülen kişi kimdir? (Lütfen olası tüm uygun yanıtları işaretleyiniz.)

'Who is the person being praised? (Please, select all applicable options.)'
(a) Hamza
'Hamza'
(b) Ahmet
'Ahmet'
(c) Başka biri
'Someone else'

Fillers and experimental items appeared in a 1:1 ratio. Of the nine filler items, six were referentially unambiguous and three were two- or three- way ambiguous. Like the experimental sentences, all fillers were followed by three response options. An unambiguous filler is illustrated in (8):
Duygu, Gamze'nin hasta olduğunu
yeni öğrendi.
Duygu Gamze.Gen ill become.N.3SG.POSS.ACC new learned
'Duygu has just found out that Gamze is ill.'

Hasta olan kişi kimdir? (Lütfen olası tüm uygun yanıtları işaretleyiniz.)

'Who is ill? (Please, select all applicable options.)'
(a) Duygu
'Duygu'
(b) Gamze
'Gamze'
(c) Başka biri
'Someone else'

Experimental items were distributed across three lists in a Latin Square design, such that participants only saw one anaphor for each sentence but the three possible combinations of experimental sentences and anaphors appeared across lists. Experimental and filler items were randomized by list. Prior to the experiment, participants completed a detailed demographic questionnaire and were given instructions together with a three-way ambiguous practice item, which emphasized that more than one response option was possible. There was no response deadline. The experiment was run on a web-based platform using Ibex Farm (Drummond, 2013). Web-based testing was used because it allowed us to expand our participant pool by recruiting heritage speakers across Germany, and because this method has been found to yield reliable results in previous psycholinguistics studies (Chemla et al., 2016; Dillon et al., 2014; Enochson and Culbertson, 2015; Gibson et al., 2011; Sprouse, 2011; Wagers and Phillips, 2014). 


\section{Analysis}

Each response option was coded as 1 (if the option was selected) or 0 (if the response was not selected). The accuracy of the filler items was computed based only on the unambiguous trials, which constituted the majority of the fillers. Only participants with accuracy higher than $70 \%$ in the filler trials were included in the analysis. The analysis was performed using mixed-effects logistic regression (Jaeger, 2008). We examined whether the proportion of choices towards local, long-distance, and extra-sentential antecedents differed as a function of the type of anaphor. For each type of antecedent choice (local/long-distance/extra-sentential) two models were run. The first model used as a baseline the proportion of antecedent choices when the anaphor was kendi, and it compared it sequentially with the proportion of antecedent choices when the anaphors were kendisi and $o$. To compute the third comparison (kendisi vs. $o$ ), the model was re-levelled and antecedent choices with kendisi were used as a baseline (for previous work using relevelling, see Farhy et al., 2017; Jacob et al., 2017).

For the random effects structure of the model we followed current guidelines in psycholinguistics and we initially constructed a maximal model that included random intercepts and slopes by participants and items (Barr et al., 2013). When these models failed to converge, they were gradually simplified until convergence was achieved. Specifically, by-item slopes were removed in the analysis of responses to long-distance antecedents and by-participant slopes were removed in the analysis of responses to extra-sentential antecedents.

We report effect sizes using the model estimates $(\hat{\beta})$, their standard error $(S E)$, and $z$ - and $p$-values in the tables below. Analyses were performed with $\mathrm{R}$ (R Development Core Team, 2018). P-values were computed using Satterthwaite's approximation for denominator degrees of freedom with the lmerTest package (Kuznetsova et al., 2014). Note that the figures and text display the experimental effects in percentages for easier interpretability, but the accuracy analyses were always performed on log odds.

\section{Results}

Mean accuracy in the filler trials was $70 \%$ ( $\mathrm{SD}=13.29 \%)$. In sentences with kendi, participants preferred local and long-distance antecedents to extra-sentential ones $(83 \%$, $55 \%$, and $3 \%$ respectively). When the anaphor was kendisi, participants also preferred local and long-distance antecedents to extra-sentential ones $(75 \%, 80 \%$, and $3 \%$ respectively). Finally, in sentences with $o$, participants preferred long-distance and extra-sentential antecedents over local ones $(92 \%, 63 \%$, and $7 \%$ respectively).

FIGURE 1 shows participants' antecedent choices as a function of the type of anaphor. The model results (TABLE 1) showed that participants were more likely to choose local antecedents for kendi and kendisi than for $o$, while long-distance antecedents were chosen more often for kendisi and $o$ than for kendi. Finally, extra-sentential antecedents were chosen more often for $o$ than for the other two anaphors. 

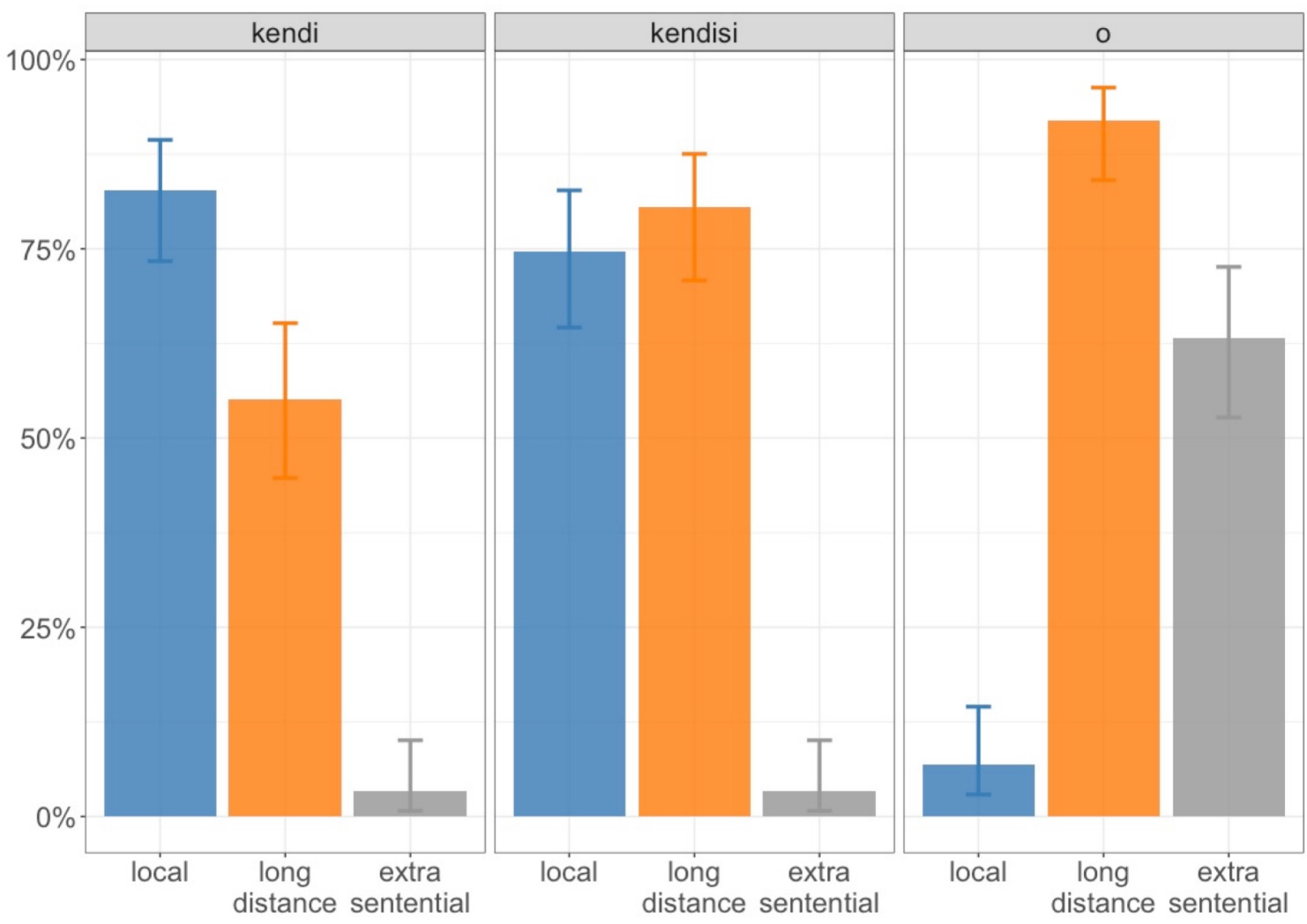

\section{Antecedent choice}

FIGURE 1. Proportion of antecedent choices in Experiment 1 (antecedent choice task). The rate of preferences (shown by the height of each bar) was computed as the number of selected responses over the total number of experimental trials. Each anaphor is plotted in a separate panel. Error bars correspond to $95 \%$ binomial confidence intervals. Note that for each anaphor, the height of the added bars exceeds $100 \%$ because multiple responses per trial were allowed.

TABLE 1. Model results for Experiment 1 (antecedent choice task). Model estimates $(\hat{\beta})$ and standard errors $(S E)$ are expressed in log odds units. Significant effects at the $\alpha=.05$ level are bolded.

\begin{tabular}{|c|c|c|c|c|c|c|c|c|c|c|c|c|}
\hline & \multicolumn{12}{|c|}{ Antecedent choice } \\
\hline & \multicolumn{4}{|c|}{ Local } & \multicolumn{4}{|c|}{ Long-distance } & \multicolumn{4}{|c|}{ Extra-sentential } \\
\hline & $\hat{\beta}$ & SE & $z$ & $p$ & $\hat{\beta}$ & $\mathrm{SE}$ & $z$ & $p$ & $\hat{\beta}$ & SE & $z$ & $p$ \\
\hline kendi vs. kendisi & 1.44 & 2.2 & 0.67 & .505 & 2.34 & 1.02 & 2.30 & .021 & 0.00 & 1.18 & 0.00 & .998 \\
\hline kendi vs. o & -4.92 & 0.95 & -5.18 & .000 & 6.00 & 2.67 & 2.25 & .025 & 6.83 & 1.44 & 4.74 & .000 \\
\hline kendisi vs. o & -6.37 & 2.29 & -2.78 & .005 & 3.66 & 2.84 & 1.29 & .197 & 6.84 & 1.46 & 4.68 & .000 \\
\hline
\end{tabular}




\section{Discussion}

Experiment 1 tested the interpretative possibilities of kendi, kendisi, and $o$ in sentences without any preceding context. We examined whether Turkish heritage speakers simplified the distinctions of the monolingual grammar, by either failing to treat kendisi as globally ambiguous, or by disallowing long-distance binding with reflexives, as predicted by processing principles that favor small domains in the computation of syntactic dependencies (Hawkins 1994, 2004). Our results showed that, as expected, heritage speakers resolved $o$ towards long-distance and extra-sentential antecedents, and dispreferred local antecedents. Further, they showed a complementary profile with reflexives, by dispreferring extra-sentential antecedents and preferring local and longdistance antecedents for kendisi and, to a lower extent, kendi as well. This finding is consistent with previous findings with Turkish monolinguals, which showed that kendi and kendisi both admit local and long-distance antecedents (Gračanin-Yuksek et al., 2017; Özbek and Kahraman, 2016). However, in contrast with the study by Gračanin-Yuksek and colleagues (2017), heritage speakers were also more likely to select long-distance antecedents with kendisi than with kendi, showing some distinction between these anaphors. Importantly, since long-distance antecedents were allowed for both kendi and kendisi, our results suggest that speakers did not fully simplify their binding properties of reflexives.

However, heritage speakers showed some evidence of simplification because they rarely selected extra-sentential antecedents for kendisi. A priori, this behavior suggests that they did not recognize kendisi as three-way ambiguous, which is consistent with previous work in which heritage speakers recognized the ambiguity of kendisi to a relatively low degree (Gürel and Yılmaz, 2011). However, Gračanin-Yuksek and colleagues (2017) showed that the unavailability of extra-sentential antecedents for kendisi in Turkish monolinguals was likely a by-product of the lack of context in the antecedent selection task, which violated the pragmatic constraint of kendisi to refer to antecedents already introduced in the discourse (Enç, 1983). Given this pragmatic restriction, it is possible that heritage speakers' avoidance of extra-sentential antecedents for kendisi resulted from the nature of the task, rather than being an indication of true grammatical simplification. Gračanin-Yuksek and colleagues addressed this concern by conducting a self-paced reading task, where sentences followed contexts that introduced the extra-sentential antecedent in the discourse. We replicated this experiment with heritage speakers in order to test whether a pragmatically appropriate use of kendisi would enhance the availability of co-reference with extra-sentential antecedents. In addition, the use of a reading paradigm was motivated by previous work on second language processing, which has shown that online measures can sometimes provide evidence for distinctions not found in untimed tasks (Clackson et al., 2011; Felser and Cunnings, 2012; Felser et al., 2009; Lago et al., 2018; Pan and Felser, 2011). 


\section{Experiment 2}

\section{Participants}

A new group of heritage speakers was recruited from Turkish-speaking communities in Berlin. The exclusion of four participants with low filler accuracy yielded fifty participants (mean age $=27$ years, age range $=18-44,34$ females, 44 right-handed). All heritage speakers had acquired Turkish from birth and German before puberty (mean $=3.28$ years, $\mathrm{SD}=2.91$ years). All participants had completed their secondary education, with thirty having also obtained a university or tertiary degree and four a postgraduate degree. As in Experiment 1, the majority of speakers reported use of both Turkish and German. In addition, they rated how often they used these languages during an average week. The reported frequency of use of Turkish was $42 \%(\mathrm{SD}=17 \%)$ and of German $50 \%$ (SD $=16 \%$ ). Their knowledge of Turkish was assessed using the grammar subtest of the telc Turkish $\mathrm{C} 1$ test (telc $\mathrm{GmbH}$ ). This subtest was a multiple-choice cloze test with a maximum score of 22, requiring participants to choose the correct word form depending on the sentence structure (mean score $=69 \%$; SD $=16 \%$ ). Their knowledge of German was evaluated by the Goethe Institut Placement Test (Goethe Institut, 2010), which required participants to solve 30 multiple choice questions about grammar and vocabulary (mean score $=84 \% ; \mathrm{SD}=11 \%$ ). In contrast with Experiment 1, participants did not self-evaluate their proficiency in Turkish and German, and thus we were not able to compare the language proficiency of the two groups using the same measure, which is a limitation of the current study.

\section{Materials and procedure}

Materials were based on the nine experimental sentences in Experiment 1, but the target sentence was preceded by a two-sentence dialogue context. There were twenty-seven item sets: nine contained kendi, nine kendisi, and nine $o$ (TABLE 2). The item sets were developed by repeating each context three times with minimal changes, such that each target sentence appeared once with kendi, once with kendisi and once with $o$. For instance, hurt my mother in item 1 (kendi) was changed to yelled at my father in item 10 (kendisi) and upset my brother in item $20(o)$. The purpose of the contexts was to bias participants to resolve the anaphor towards one of the three individuals mentioned in the dialogue. Two of these individuals corresponded to intra-sentential antecedents (the matrix and embedded subjects) and one was an extra-sentential antecedent, i.e., an individual not mentioned in the target sentence but mentioned in the dialogue. The bias of the context was either compatible or incompatible with the syntactic constraints of the anaphor. The structure of the contexts and target sentences was identical across items.

Experimental items were distributed across three lists in a Latin Square design, such that each version of an item appeared only once per list and was preceded by contexts with different biases across lists. The experimental items were pseudo-ordered, so that participants never saw more than three consecutive experimental items. They were interspersed with fifty-four newly-constructed fillers, which also contained a two-sentence dialogue and a target sentence. 
Experimental and filler sentences were presented by regions, as illustrated in (9). In the experimental sentences, the first region contained the long-distance antecedent, the second region the local antecedent, and the third region the anaphor. The anaphor was followed by the embedded verb, a one- or two-word interjection, and the matrix verb.

(9) Cem: Ne kadar aptalım! Keşke annemi kırmasaydım.

Emre: Olur böyle şeyler.

'Cem: I am so stupid! I wish I hadn't hurt my mother.

Emre: These things happen.'

Emre, / Cem'in / kendisini / suçladığını / bir anda / anladı.

Emre / Cem.GEN / kendisi.ACC / blame.N.3SG.POSS.ACC / one moment.LOC / understood

'Emre realized right away that Cem is blaming him/himself.'

All experimental items and half of the fillers were followed by an end-of-trial comprehension question: half of the questions asked about the context and half asked about the target sentence.

The experiment was presented by the E-prime experimental software (Schneider et al., 2002a, b) in a visual self-paced non-cumulative moving window design (Just et al., 1982). Sentences appeared in white letters on a black background in 18-point Arial font. Before the experiment, participants were instructed to read for comprehension and at a normal pace and they completed three practice items to familiarize themselves with the task. Each trial began with a screen with words masked by dashes. The first press of the space bar displayed the dialogue conveying the context bias. The second key press remasked the dialogue and revealed the first word of the target sentence. With each key press, the subsequent region was revealed and the previous region was re-masked. The reading time for each region was measured as the time difference between two successive key presses. After half of the trials, participants were offered a break. After the completion of the task, participants filled out the demographic questionnaire and Turkish and German proficiency tests. Each experimental session took about 35-45 minutes. 
TABLE 2. Sample sets of three item sets in Experiment 2 (self-paced reading task).

\begin{tabular}{|c|c|c|c|c|c|}
\hline Item & Anaphor & Bias & & & $\begin{array}{l}\text { Experimental } \\
\text { sentence }\end{array}$ \\
\hline & & Local antecedent & Long distance antecedent & Extra-sentential antecedent & \\
\hline \multirow{3}{*}{1} & \multirow{3}{*}{ kendi } & Cem: Ne kadar aptalım! Keşke & Cem: Ne kadar kabasın! Keşke & & Emre, Cem'in kendini \\
\hline & & Emre: Olur böyle seyler. & Emre: Olur böyle seyler. & Keşкe annesinı kırmasay & anladi. \\
\hline & & $\begin{array}{l}\text { Cem: I am so stupid! I wish I } \\
\text { hadn't hurt my mother. } \\
\text { Emre: These things happen. }\end{array}$ & $\begin{array}{l}\text { Cem: You are so rude! I wish you } \\
\text { hadn't hurt your mother. } \\
\text { Emre: These things happen. }\end{array}$ & $\begin{array}{l}\text { Cem: Ali is so rude! I wish } \\
\text { he hadn't hurt his mother. } \\
\text { Emre: These things happen. }\end{array}$ & $\begin{array}{l}\text { Emre realized right } \\
\text { away that Cem is } \\
\text { blaming kendi. }\end{array}$ \\
\hline \multirow[t]{2}{*}{10} & \multirow[t]{2}{*}{ kendisi } & $\begin{array}{l}\text { Alp: Ne kadar aptalim! Keşke } \\
\text { babama bağırmasaydım. } \\
\text { Kaya: Olur böyle şeyler. }\end{array}$ & $\begin{array}{l}\text { Alp: Ne kadar kabasın! Keşke babana } \\
\text { bağırmasaydın. } \\
\text { Kaya: Olur böyle şeyler. }\end{array}$ & $\begin{array}{l}\text { Alp: Fikret ne kadar kaba! } \\
\text { Keşke babasına bağırmasaydı. } \\
\text { Kaya: Olur böyle şeyler. }\end{array}$ & $\begin{array}{l}\text { Kaya, Alp'in kendisini } \\
\text { suçladığını bir anda } \\
\text { anladı. }\end{array}$ \\
\hline & & $\begin{array}{l}\text { Alp: I am so stupid! I wish I } \\
\text { hadn't yelled at my father. } \\
\text { Kaya: These things happen. }\end{array}$ & $\begin{array}{l}\text { Alp: You are so rude! I wish you } \\
\text { hadn't yelled at your father. } \\
\text { Kaya: These things happen. }\end{array}$ & $\begin{array}{l}\text { Alp: Fikret is so rude! I wish } \\
\text { he hadn't yelled at his father. } \\
\text { Kaya: These things happen. }\end{array}$ & $\begin{array}{l}\text { Kaya realized right } \\
\text { away that Alp is } \\
\text { blaming kendisi. }\end{array}$ \\
\hline \multirow[t]{2}{*}{20} & \multirow[t]{2}{*}{$o$} & $\begin{array}{l}\text { Melih: Kuzenim için çektiğim } \\
\text { fotoğraf mükemmel! Ben } \\
\text { inanılmaz yetenekliyim. } \\
\text { Özgür: Bence de güzel bir } \\
\text { fotoğraf. }\end{array}$ & $\begin{array}{l}\text { Melih: Kuzenin için çektiğin fotoğraf } \\
\text { mükemmel! Sen inanılmaz } \\
\text { yeteneklisin. } \\
\text { Özgür: Bence de güzel bir fotoğraf. }\end{array}$ & $\begin{array}{l}\text { Melih: Soner'in kuzeni için } \\
\text { çektiği fotoğraf mükemmel! } \\
\text { İnanılmaz yetenekli. } \\
\text { Özgür: Bence de güzel bir } \\
\text { fotoğraf. }\end{array}$ & $\begin{array}{l}\text { Özgür, Melih'in onu } \\
\text { övdüğunü kolayca fark } \\
\text { etti. }\end{array}$ \\
\hline & & $\begin{array}{l}\text { Melih: The photograph that I } \\
\text { took for my cousin is } \\
\text { wonderful. I am very talented. } \\
\text { Özgür: I also think this is a } \\
\text { nice photo. }\end{array}$ & $\begin{array}{l}\text { Melih: The photograph that you took } \\
\text { for your cousin is wonderful. You are } \\
\text { very talented. } \\
\text { Özgür: I also think this is a nice } \\
\text { photo. }\end{array}$ & $\begin{array}{l}\text { Melih: The photograph that Soner } \\
\text { took for his cousin is wonderful. } \\
\text { He is very talented. } \\
\text { Özgür: I also think this is a nice } \\
\text { photo. }\end{array}$ & $\begin{array}{l}\ddot{O}_{z g u ̈ r} \text { easily realized } \\
\text { that Melih is praising } \\
\underline{\underline{o}}\end{array}$ \\
\hline
\end{tabular}




\section{Analysis}

We followed the same data cleaning procedures as Gračanin-Yuksek et al. (2017). Only participants with more than $70 \%$ accuracy in the filler trials were entered into the analysis (Lago et al, 2015; Parker et al., 2015). Reaction times faster than $200 \mathrm{~ms}$ or slower than $3000 \mathrm{~ms}$ were excluded. These cut-off points were based on previous literature: Reaction times faster than $200 \mathrm{~ms}$ are unlikely to reflect cognitive processing since the process of visual word recognition takes 200-250 ms on average (Clifton et al., 2007; Rayner, 1998). Reaction times slower than $2500 \mathrm{~ms}$ are typically excluded in self-paced reading studies (e.g., Hofmeister, 2011; Vasishth and Drenhaus, 2011). For our study, we increased the upper boundary to $3000 \mathrm{~ms}$ to ensure that outlier removal affected less than $10 \%$ of the data in each region. This trimming procedure affected $3.07 \%$ of the data at the anaphor region, $6.81 \%$ of the data at the critical region and $2.67 \%$ of the data at the final sentence region. The remaining reading times were analyzed using linear mixed-effects models (Baayen et al., 2008). Reading times were log transformed, as suggested by the Box-Cox method (Box and Cox, 1964) performed on the reading times pooled across regions.

As in Gračanin-Yuksek et al. (2017), the regions of interest consisted of the embedded verb and following regions. Note that due to Turkish word order, the verb region was the first point where participants could assess the compatibility between the target sentence and the preceding context (e.g., Emre Cem kendi blame....). Prior to the verb, at the point of the anaphor, the target sentence was neither consistent nor inconsistent with the preceding context. However, since the anaphor region was the earliest point where the antecedent search could begin, we report the results for this region in the text for completeness. Importantly, as it has been recently argued that the analysis of multiple regions can increase the likelihood of Type 1 errors (von der Malsburg and Angele, 2016), reaction times to the embedded verb and following adverb were merged on a by-trial basis in order to define a unique critical region and avoid a multiple comparisons issue. The length and position of this critical region was identical across conditions. The last word of the sentence, the matrix verb, was preserved as a single region because reading times in sentence final regions should be interpreted with care, as they can be subject to wrap-up effects (Just and Carpenter, 1980). However, due to the verb-finality of Turkish and the nature of our materials, we could not insert further material to probe for the effects of interest prior to the final region.

The reading time analysis was done in two stages. First, we examined whether the biasing context differentially affected reading times for each type of anaphor. For this purpose, two models were compared. The first model included main effects of ANAPHOR (o/kendi/kendisi) and CONTEXT BIAS (local/long-distance/extra-sentential) but no interaction between them. By contrast, the second model assessed whether the effect of the context differed for each anaphor by including both main effects and their interaction. Likelihood ratio tests were used to assess which model provided a better fit to the data (Baayen et al., 2008).

In the second stage, reading times for $o$, kendi, and kendisi were examined separately using a model with a fixed effect of CONTEXT BIAS (local/long-distance/extrasentential). For each anaphor, reading times in the three contexts were directly compared to each other: (i) local vs. long-distance, (ii) local vs. extra-sentential and (iii) long- 
distance vs. extra-sentential. In order to compute the first two comparisons, the local biasing context was used as a baseline and compared with the two other context conditions. To compute the third comparison (iii), the model was re-leveled and the long-distance biasing context was used as a baseline. A maximal random effects structure was used, including random intercepts and slopes by participants and items. We present the model estimates $(\hat{\beta})$, their standard error (SE), and $t$ - and $p$-values in the tables below.

\section{Results}

\section{Model comparison}

The model that included an interaction between the type of anaphor and the bias of the context provided a significantly better fit to the data compared to the additive model in both the critical and final sentence regions (critical: $\chi^{2}{ }_{(4)}=26.20, p=.000$; final: $\chi^{2}{ }_{(4)}=$ $24.26, p=.000)$. These results show that the biasing contexts affected the anaphors differently, and thus the three anaphors were analyzed separately. Importantly, the model with an interaction was not significantly better than the additive model in the pre-critical region (anaphor: $\chi^{2}{ }_{(4)}=4.05, p=.400$ ), which shows that the differential effect of the context only emerged at the embedded verb.

TABLE 3. Linear mixed-effects estimates for the regions of interest in Experiment 2 (selfpaced reading task). Model estimates $(\hat{\beta})$ and standard errors $(S E)$ are expressed in log units.

\begin{tabular}{|c|c|c|c|c|c|c|c|c|c|c|c|c|}
\hline & \multicolumn{4}{|c|}{ kendi } & \multicolumn{4}{|c|}{ kendisi } & \multicolumn{4}{|c|}{$o$} \\
\hline & $\hat{\beta}$ & $S E$ & $t$ & $p$ & $\hat{\beta}$ & $S E$ & $t$ & $p$ & $\hat{\beta}$ & $S E$ & $t$ & $p$ \\
\hline \multicolumn{13}{|l|}{ Critical region } \\
\hline local vs. long-distance & 0.04 & 0.06 & 0.73 & .485 & 0.00 & 0.05 & -0.08 & .936 & -0.09 & 0.05 & -1.92 & .066 \\
\hline $\begin{array}{l}\text { local vs. extra-sentential } \\
\text { long-distance vs. extra- }\end{array}$ & 0.13 & 0.05 & 2.39 & .041 & 0.02 & 0.05 & 0.48 & .641 & -0.16 & 0.07 & -2.23 & .046 \\
\hline sentential & 0.08 & 0.05 & 1.65 & .107 & 0.03 & 0.04 & 0.69 & .493 & -0.07 & 0.06 & -1.21 & .259 \\
\hline \multicolumn{13}{|l|}{ Final region } \\
\hline local vs. long-distance & 0.08 & 0.06 & 1.33 & .216 & -0.02 & 0.07 & -0.24 & .816 & -0.19 & 0.06 & -3.10 & .008 \\
\hline $\begin{array}{l}\text { local vs. extra-sentential } \\
\text { long-distance vs extra- }\end{array}$ & 0.08 & 0.07 & 1.25 & .244 & -0.06 & 0.08 & -0.66 & .525 & -0.23 & 0.08 & -2.88 & .017 \\
\hline sentential & 0.01 & 0.06 & 0.09 & .931 & -0.04 & 0.05 & -0.80 & .423 & -0.04 & 0.07 & -0.58 & .578 \\
\hline
\end{tabular}




\section{$\underline{\text { Kendi }}$}

No differences were found at the anaphor. In the critical region, participants showed increased processing difficulty when kendi was preceded by an extra-sentential biasing context, as compared to the local biasing context. TABLE 3 shows the statistical results and FIGURE 2 shows by-region reading time averages.

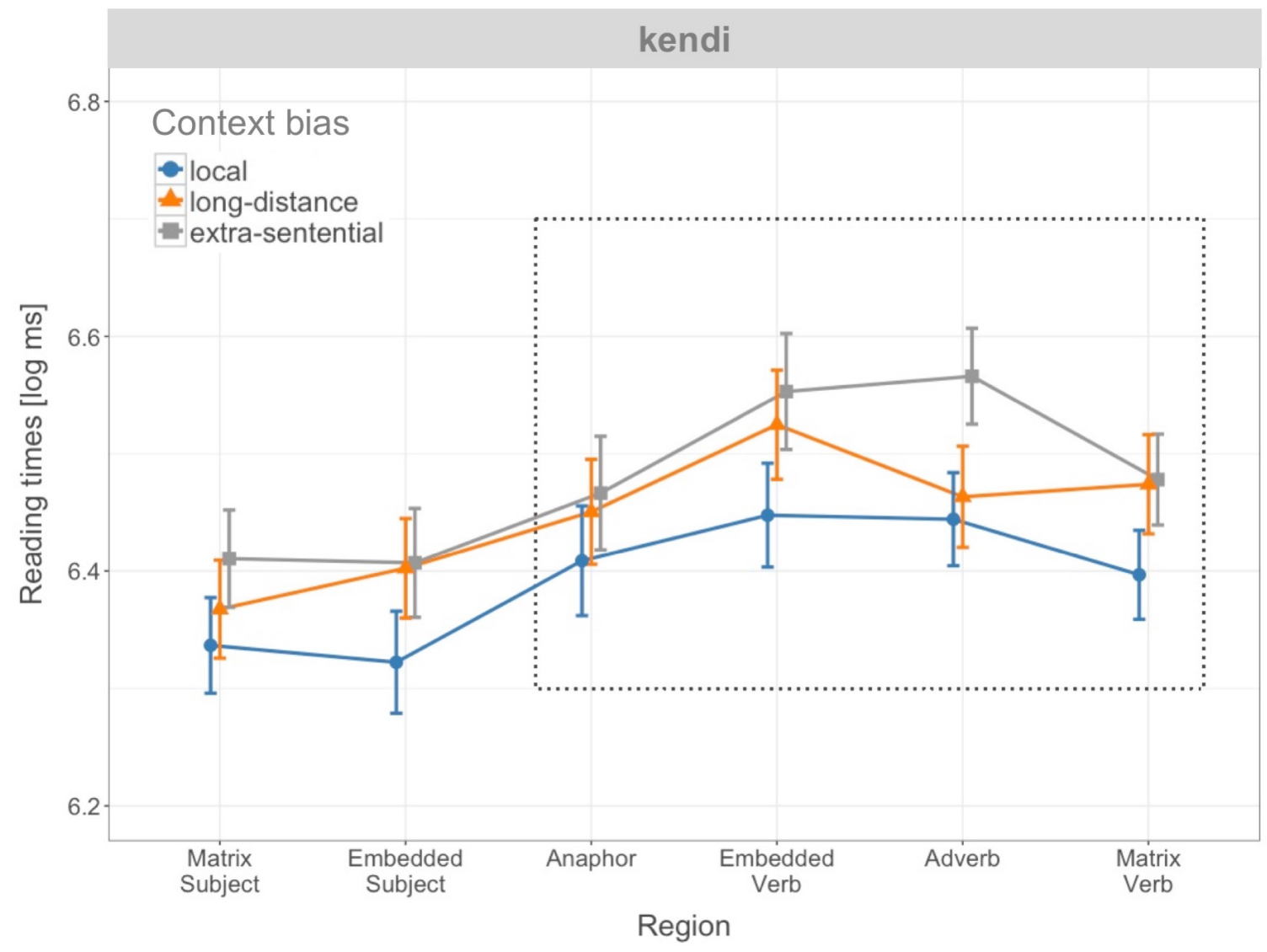

FIGURE 2. By-region reading times averages for kendi in Experiment 2 (self-paced reading task). Error bars indicate the standard error of the mean.

\section{$\underline{\text { Kendisi }}$}

No differences were found at the anaphor. Further, there were no differences between conditions in any of the regions of interest, yielding no evidence that the processing of kendisi differed as a function of the preceding context (FIGURE 3). 


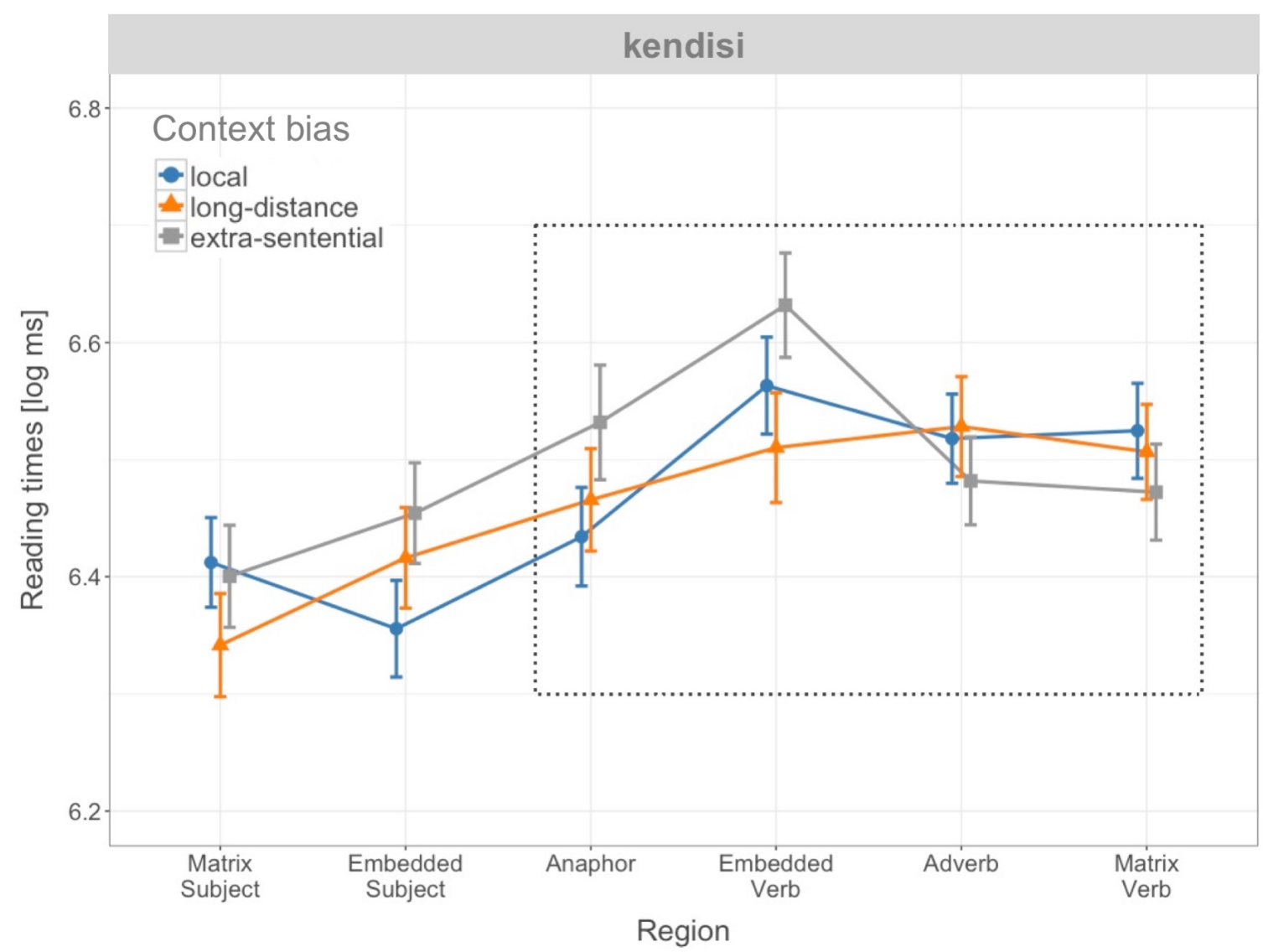

FIGURE 3. By-region reading time averages for kendisi in Experiment 2 (self-paced reading task). Error bars indicate the standard error of the mean.

\section{$\mathrm{O}$}

No differences were found at the anaphor. In the critical and final regions, participants showed increased processing difficulty when $o$ was preceded by a local biasing context, as compared to the extra-sentential context (FIGURE 4). Further, the local condition also elicited more processing difficulty than the long-distance condition, an effect that was marginal in the critical region and significant in the final region. 


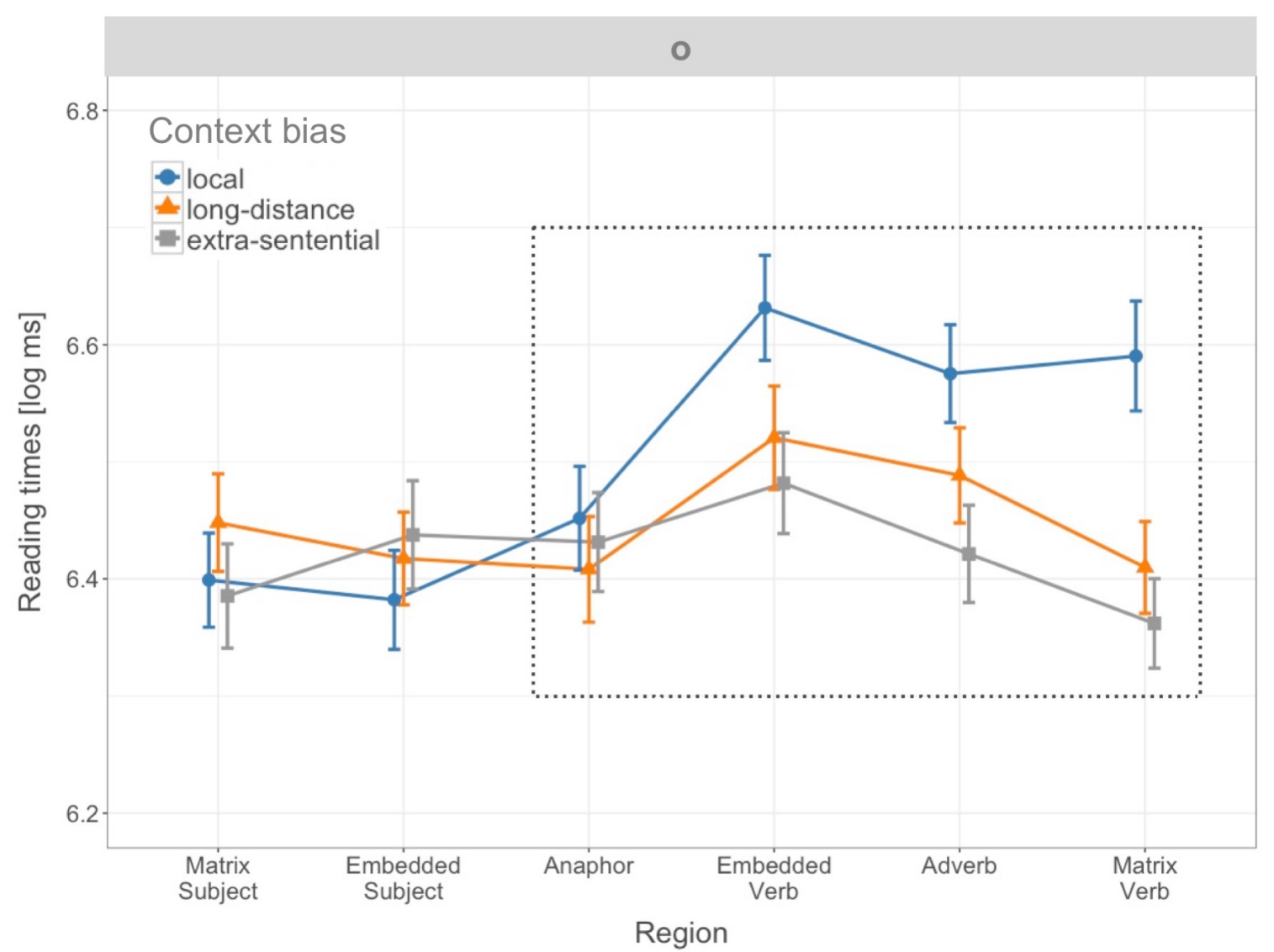

FIGURE 4. By-region reading time averages for $o$ in Experiment 2 (self-paced reading study). Error bars indicate the standard error of the mean.

\section{Discussion}

Experiment 2 tested the interpretative possibilities of kendi, kendisi, and $o$ when preceded by biasing contexts that were consistent or inconsistent with the syntactic constraints of the anaphors. Our results showed that heritage speakers experienced reading disruptions with kendi after contexts favoring extra-sentential antecedents and with $o$ after contexts favoring local antecedents. Crucially, sentences with kendisi were read equally quickly in contexts with local, long-distance, and extra-sentential bias, suggesting that participants could accommodate the interpretation of kendisi in all contexts.

It is worth noting that, in contrast with the findings of Experiment 1, where speakers allowed extra-sentential antecedents for kendisi only $4 \%$ of the time, Experiment 2 showed that kendisi could be resolved towards an extra-sentential antecedent without additional processing effort, as long as the antecedent had been previously introduced in the discourse. Crucially, the fact that heritage speakers allowed non-local interpretations of kendisi, as well as long-distance interpretations of kendi, indicates that they did not turn the tripartite anaphoric system of the monolingual Turkish grammar, into a simpler, two-way distinction system, which would be consistent with the societally-dominant German and also with efficiency principles favoring smaller binding domains. The General Discussion explores the implications of these findings. 


\section{General Discussion}

Our experiments examined heritage Turkish speakers' interpretation of the anaphors kendi, kendisi and $o$ using an offline judgment task and a self-paced reading task. Converging results were obtained for kendi and $o$ across experiments: Participants preferred local and long-distance antecedents for kendi in Experiment 1, and reading times were facilitated after contexts favoring local antecedents in Experiment 2. Similarly, long-distance and extra-sentential antecedents were preferred for $o$ in Experiment 1, and reading times were facilitated after contexts favoring these antecedents in Experiment 2. Kendisi showed similar antecedent preferences to kendi in Experiment 1, in that extra-sentential antecedents were frequently rejected but local and long-distance antecedents were accepted (although a stronger long-distance preference was observed for kendisi than kendi). But in the selfpaced reading task, participants behaved similarly in all biasing contexts with kendisi, which suggests that coreference with extra-sentential antecedents was allowed.

Following Gračanin-Yuksek and colleagues (2017), we attribute the reduced number of extra-sentential antecedent choices for kendisi in Experiment 1 to the absence of a previously introduced discourse referent, rather than to a syntactic restriction (Enç, 1983). However, we note that the two experiments were not minimally different: on the one hand, they differed in the presence versus the absence of the context and on the other, they differed in whether a timed or untimed paradigm was used, and whether this paradigm required explicit judgments or relied on implicit reading measures. To dissociate the role of these factors, future work could use offline judgments to anaphors preceded by sentence context, to examine whether in these circumstances kendisi still shows a dispreference for extra-sentential antecedents.

Our results show that the Turkish heritage system, which allows reflexives to be locally and long-distance (kendi, kendisi), as well as discourse bound (kendisi), did not get simplified to the system found in German, in which reflexives must be locally bound. Such a change would be in line with observations that some parts of heritage grammars are less complex than their monolingual counterparts, as has been reported in the areas of quantifier scope (Ronai, 2017; Scontras et al., 2017; Tsai et al., 2014) and case morphology (Polinsky, 2006). Note that grammatical simplification is expected under accounts in which the use of a simpler system decreases processing load (Hawkins, 2004), but not under accounts in which simplification occurs exclusively for constructions that are in competition with corresponding constructions in the societally-dominant language (Gürel, 2004; Paradis, 1993, 2007). Our results suggest that, contrary to the predictions of Hawkins' account, the referential possibilities of reflexives that lack a corresponding form in the dominant language may be preserved under heritage language conditions, even when these forms increase the processing load of the parser in comprehension.

Our findings are consistent with previous literature on anaphor resolution in heritage languages, which reported that heritage speakers preserved the anaphoric distinctions of the monolingual grammar (Gürel, 2002, 2004; Gürel and Yilmaz, 2011; Kim et al., 2009, 2010). However, it is important to acknowledge several differences between these studies and ours. First, we did not evaluate the performance of heritage speakers using a separate group of monolingual speakers. We wanted to avoid comparing two groups whose reading behavior would likely differ due to different degrees of formal instruction in Turkish and distinct reading fluency. Therefore, our results cannot establish whether 
heritage speakers preserve anaphoric distinctions to the same extent as monolingual speakers. Rather, what our findings show is that the distinctions present in the monolingual grammar are not collapsed or simplified in the heritage grammar, even in a language contact situation.

A second difference is that our study used a paradigm that facilitated tapping into participants' implicit grammatical sensitivity, enabling the detection of not only distinctions that were preferred (as antecedent choice tasks do) but also those that were allowed, even if dispreferred. Remarkably, our participants were able to evaluate the compatibility between the antecedents preferred by the anaphors and those favored by the context even though the experimental paradigm relied heavily on their reading skills in Turkish. Since formal literacy training in a heritage language is a significant predictor of how heritage speakers perform compared to monolinguals (Bayram et al., 2017; Kupisch and Rothman, 2016), it will be important for future work to evaluate modalities that do not require formal training, such as listening and speaking.

Moreover, since we measured participants' online processing (as indexed by their reading times) we were able to make inferences about their grammar on the basis of their processing profiles, rather than their final antecedent choices. This is important because online measures can reveal patterns that are not obvious in offline judgments, as shown by research on both monolingual speakers and second language learners (e.g., Felser and Cunnings, 2012; Felser et al., 2009; Sturt, 2003). Therefore, we suggest that the combination of biasing contexts and the self-paced reading methodology may have played an important role in allowing participants to establish all grammatically licensed dependencies between anaphors and antecedents.

To conclude, our findings indicate that the heritage Turkish grammar preserves the binding possibilities of the monolingual grammar, conserving the syntacticallyunconstrained reflexive kendisi, preventing the pronoun $o$ from being locally bound and the reflexive kendi from taking extra-sentential antecedents. Future work could build on these results by testing modalities that do not require literacy and by examining a less proficient heritage group, in order to assess the role of individual differences in anaphoric processing. Importantly, our findings do not rule out the possibility that Turkish heritage speakers may use anaphoric categories differently than monolingual speakers, which would result in diverging interpretive preferences. If this is the case, and if performance limitations can eventually lead to grammatical restructuring, then such differences might be an indication that the grammatical competence of heritage speakers may eventually undergo a change, resulting in the ultimate simplification of the anaphoric system over a longer time span, a possibility that could be addressed by testing future generations of Turkish heritage speakers. Thus, research on heritage languages that combines testing what is allowed and what is preferred has the potential to be highly informative in identifying mechanisms that underlie not only variation induced by language contact, but language change more generally.

\section{Notes}

${ }^{1}$ In a limited set of contexts, sich allows non-local binding (e.g., in the so-called 'Accusativus cum Infinitivo', in which the embedded infinitival clause is typically embedded under a perception verb; see Lee-Schoenfeld (2004)). However, outside of this 
context, the reflexive sich and the corresponding pronouns are in complementary distribution.

\section{Acknowledgments}

We thank Gloria-Mona Knospe and Claudia Felser for their valuable contributions to the project and Semra Kizllkaya for her help during participant recruitment.

\section{Funding information}

This research was supported by an Alexander-von-Humboldt professorship awarded to Harald Clahsen and by TÜBITAK, the Scientific and Technological Research Council of Turkey (grant number: 113K458) awarded to Bilal Kırkıc1. Sol Lago was supported in part by a German Research Council project (grant number LA 3774/1-1).

\section{References}

Aalberse S and Muysken P (2013) Perspectives on heritage languages. Position paper presented at the Leeuwenhorst Workshop on Heritage Languages, January $23^{\text {rd }}$ 25th, 2013.

Albirini A, Chakrani B and Benmamoun E (2013) Gender and Number Agreement in the Oral Production of Arabic. Language and Cognition 16(1): 1-18.

Baayen RH, Davidson D J and Bates DM (2008) Mixed-effects modeling with crossed random effects for subjects and items. Journal of Memory and Language, 59: 390412.

Barr DJ, Levy R, Scheepers C and Tily H (2013) Random-effects structure for confirmatory hypothesis testing: Keep it maximal. Journal of Memory and Language 68(3): 255-278.

Bayram F, Rothman J, Iverson M, Miller D, Puig Mayenco E, Kupisch T and Westergaard M (2017) Differences in use without deficiencies in competence: passives in the Turkish and German of Turkish heritage speakers in Germany. International Journal of Bilingual Education and Bilingualism 32: 1-21.

Benmamoun E, Montrul S and Polinsky M (2013) Heritage languages and their speakers: Opportunities and challenges for linguistics. Theoretical Linguistics 46: 129-181.

Ben Rafael M (2004) Language contact and attrition: The spoken French of Israeli Francophones. In: Schmid MS, Köpke B, Keijzer M and Weilemar L (eds.) First Language Attrition: Interdisciplinary perspectives on methodological issues. Amsterdam: John Benjamins, pp. 165-188.

Berwick R (1985) The Acquisition of Syntactic Knowledge. Cambridge, MA: MIT Press.

Blanche P and Merino BJ (1989) Self-Assessment of Foreign-Language Skills: Implications for Teachers and Researchers. Language Learning 39(3): 313-338.

Box GEP and Cox DR (1964) An analysis of transformations. Journal of the Royal Statistical Society, Series B (Methodological) 26: 211-252.

Cem Değer A (1996) Türkçedeki dönüşlü adılların yönetici ulamlarının tanımlanması [Identification of categories governing reflexive pronouns in Turkish]. In: Oktar L 
and Cem Değer A (eds) X. Dilbilim Kurultayı Bildirileri. Izmir: Ege Universitesi Basimevi, pp. 41-47.

Chemla E, Cummins C and Singh R (2016) Training and timing local scalar enrichments under global pragmatic pressures. Journal of Semantics 34(1): 107-126.

Chomsky N (1981) Lectures on government and binding. Dordrecht: Foris.

Clackson K, Felser C and Clahsen H. (2011) Children's processing of reflexives and pronouns in English: Evidence from eye-movements during listening. Journal of Memory and Language 65: 128-144.

Clifton C Jr, Staub A and Rayner K (2007) Eye movements in reading words and sentences. In: van Gompel RPG, Fischer MH, Murray WS and Hill RL (eds) Eye movements: A window on mind and brain. Amsterdam: Elsevier, pp. 341-372.

Dillon B, Clifton Jr C and Frazier L (2014) Pushed aside: Parentheticals and Processing. Language, Cognition and Neuroscience 29(4): 483-498. DOI: 10.1080/01690965.2013.866684

Drummond A (2013) Ibex Farm. Available at: http://spellout.net/ibexfarm/.

Enç M (1983) Anchored Expressions. In: Barlow M, Flickinger, DP and Westcoat MT (eds) Proceedings of WCFL 2. Stanford: Stanford Linguistic Association, pp. 7988.

Enç M (1989) Pronouns, licensing, and binding. Natural Language and Linguistic Theory 7: 51-92.

Enochson K and Culbertson J (2015) Collecting Psycholinguistic Response Time Data Using Amazon Mechanical Turk. PLOS ONE 10(3) doi: 10.1371/journal.pone.0116946

Farhy Y, Veríssimo J and Clahsen H (2017) Universal and particular in morphological processing: Evidence from Hebrew. Quarterly Journal of Experimental Psychology 7: 1125-1133. https://doi.org/10.1080/17470218.2017.1310917

Felser C and Cunnings I (2012) Processing reflexives in a second language: The timing of structural and discourse-level constraints. Applied Psycholinguistics 33: 571-603.

Felser C, Sato M and Bertenshaw N (2009) The on-line application of Binding Principle A in English as a second language. Bilingualism: Language and Cognition 12: 485502.

Futrell R, Mahowald K and Gibson E (2015) Large-scale evidence of dependency length minimization in 37 languages. Proceedings of the National Academy of Sciences 112(33): 10336-10341. doi: 10.1073/pnas.1502134112

George LM and Kornfilt J (1981) Finiteness and boundedness in Turkish. In: Heny FW (ed.) Binding and Filtering. Cambridge, MA: MIT Press, pp. 105-128.

Gibson E (2000) The dependency locality theory: A distance-based theory of linguistic complexity. In: Miyashita Y, Marantz A and O'Neil W (eds) Image, language, brain, Cambridge, MA: MIT Press, pp. 95-126.

Gibson E, Piantadosi S and Fedorenko K (2011) Using Mechanical Turk to obtain and analyze English acceptability judgments. Language and Linguistic Compass 5: 509-524. DOI: 10.1111/j.1749-818X.2011.00295.

Goethe Institut (2010) German Placement Test. Goethe Institut. Available at: http://www.goethe. de/cgi-bin/einstufungstest/einstufungstest.pl (accessed January 2016). 
Göksel A and Kerslake C (2005) Turkish: A comprehensive grammar. New York: Routledge.

Gračanin-Yuksek M, Lago S, Şafak DF, Demir O and Kırkıcı B (2017) The interaction of contextual and syntactic information in the processing of Turkish anaphors. Journal of Psycholinguistic Research 46: 1397-1425.

Gürel A (2002) Linguistic characteristics of second language acquisition and first language attrition: Turkish overt versus null pronouns. PhD Thesis, McGill University, Montreal, Canada.

Gürel A (2004) Selectivity in L2-induced L1 attrition: a psycholinguistic account. Journal of Neurolinguistics (17): 53-78.

Gürel A (2006) L2 acquisition of pragmatic and syntactic constraints in the use of overt and null subject pronouns. In: Slabakova R, Montrul SA and Prévost P (eds) Inquiries in linguistic development: In honor of Lydia White. Amsterdam/Philadelphia: John Benjamins, pp. 259-282.

Gürel A and Y1lmaz G (2011) Restructuring in the L1 Turkish grammar: Effects of L2 English and L2 Dutch. Language, Interaction and Acquisition 2(2): 221-250.

Hawkins JA (1994) A Performance Theory of Order and Constituency. Cambridge: Cambridge University Press.

Hawkins JA (2004) Efficiency and complexity in grammars. Oxford/New York: Oxford University Press.

Hofmeister P (2011) Representational complexity and memory retrieval in language comprehension. Language and Cognitive Processes 26: 376-405.

Irizarri van Suchtelen P (2012) Dative constructions in the Spanish of heritage speakers in the Netherlands. In: Wąsik Z and Chruszczewski PP (eds) Languages in contact 2011. Wrocław: Philological School of Higher Education in Wrocław Publishing, pp. 103-118.

Jacob G, Heyer V and Veríssimo J (2017) Aiming at the same target: A masked priming study directly comparing derivation and inflection in the second language. International Journal of Bilingualism. Epub ahead of print 1 February 2017. DOI: $10.1177 / 1367006916688333$

Jaeger TF (2008) Categorical data analysis: Away from ANOVAs (transformation or not) and towards logit mixed models. Journal of Memory and Language 59: 434-446.

Just MA and Carpenter PA (1980) A theory of reading: From eye fixations to comprehension. Psychological Review 87: 329-354.

Just MA, Carpenter PA and Woolley JD (1982) Paradigms and processes in reading comprehension. Journal of Experimental Psychology: General 111: 228-238.

Kim J-H, Montrul S and Yoon J (2009) Binding interpretations of anaphors by Korean heritage speakers. Language Acquisition 16: 3-35.

Kim J-H, Montrul S and Yoon J (2010) Dominant language influence in acquisition and attrition of binding: Interpretation of the Korean reflexive caki. Bilingualism: Language and Cognition 13: 73-84.

Köpke B. (2002) Activation thresholds and non-pathological first language attrition. In: Fabbro F (ed.) Advances in the neurolinguistics of bilingualism. Udine: Forum, pp. 119-142. 
Köpke B (2007) Language attrition at the crossroads of brain, mind, and society. In: Köpke B, Schmid MS, Keijzer M and Dostert S (eds.) Language attrition: theoretical perspectives. Amsterdam: John Benjamins, pp. 9-37.

Kornfilt J (1997) Turkish. London/New York: Routledge.

Kornfilt J (2001) Local and long-distance reflexives in Turkish. In: Cole P, Hermon G and Huang JC-T (eds.) Long-distance reflexives. New York: Academic Press, pp. 197225.

Kupisch $\mathrm{T}$ and Rothman $\mathrm{J}$ (2016) Terminology matters! Why difference is not incompleteness and how early child bilinguals are heritage speakers. International Journal of Bilingualism: 1-9. doi: 10.1177/1367006916654355

Kuznetsova A, Bruun Brockhoff P and Haubo Bojesen Christensen R (2014) lmerTest: Tests for random and fixed effects for linear mixed effect models (lmer objects of lme4 package). $\mathrm{R}$ package version 2.0-11. http://CRAN.Rproject.org/package=lmerTest.

Lago S, Shalom D, Sigman M, Lau E and Phillips C (2015) Agreement attraction in Spanish comprehension. Journal of Memory and Language 82: 133-149. DOI: 10.1016/j.jml.2015.02.002.

Lago S, Stutter AG and Felser C (2018) The role of native and non-native grammars in the comprehension of possessive pronouns. Second Language Research. DOI: $10.1177 / 0267658318770491$

Lee-Schoenfeld V (2004) Binding by phase: (Non-)complementarity in German. Journal of German Linguistics 16: 111-171.

Leisiö L (2001) Morphosyntactic Convergence and Integration in Finland Russian. PhD Thesis, University of Tampere, Finland.

Lewis RL and Vasishth S (2005) An activation-based model of sentence processing as skilled memory retrieval. Cognitive Science 29(3): 375-419.

Marian V, Blumenfeld H and Kaushanskaya M (2007) The Language Experience and Proficiency Questionnaire (LEAP-Q): Assessing language profiles in bilinguals and multilinguals. Journal of Speech, Language, and Hearing Research 50(4): 940-967.

Meral HM (2010) Some notes on Turkish pronominal anaphora. Turkish Studies 5: 535563.

Meral HM (2013) Binding as an 'A'-phenomenon'?: Some remarks from Turkish. Iberia: International Journal of Theoretical Linguistics 5: 45-68.

Miller GA and Chomsky N (1963) Finitary Models of Language Users. In: Luce RD, Bush $\mathrm{R}$ and Galanter E (eds) Handbook of Mathematical Psychology 2. New York: Wiley, pp. 419-92.

Montrul S and Sanchez-Walker N (2013) Differential Object Marking in Child and Adult Spanish Heritage Speakers. Language Acquisition: A Journal of Developmental Linguistics 20(2): 109-132.

Özbek A and Kahraman B (2016) Interpretations of Turkish reflexive pronouns kendi and kendisi. Mersin Üniversitesi Dil ve Edebiyat Dergisi 13: 71-94.

Pan HY and Felser C (2011) Referential context effects in L2 ambiguity resolution:

Evidence from self-paced reading. Lingua 121: 221-236. doi:10.1016/j.lingua.2010.08.003 
Paradis M (1993) Linguistic, Psycholinguistic, and Neurolinguistic Aspects of Interference in Bilingual Speakers: The Activation Threshold Hypothesis. International Journal of Psycholinguistics 9: 133-145.

Paradis M (2007) L1 Attrition Features Predicted by A Neurolinguistic Theory of Bilingualism. In: Kopke B, MS Schmid, M Keijzer and S Dostert (eds.) Language Attrition: Theoretical Perspectives. Amsterdam: John Benjamins Publishing, pp: 121-133.

Parker D, Lago S and Phillips C (2015) Interference in the processing of adjunct control. Frontiers in Psychology 6: 1-13.

Pires A and Rothman J (2009) Disentangling sources of incomplete acquisition: An explanation for competence divergence across heritage grammars. International Journal of Bilingualism 13(2), 211-238.

Polinsky M (1997) Cross-linguistic parallels in language loss. Southwest Journal of Linguistics 14(1-2): 87-123.

Polinsky M (2006) Incomplete acquisition: American Russian. Journal of Slavic Linguistics 14: 192-265.

Putnam M and Arnbjörnsdóttir B (2015) Minimizing (Interface) domains: The loss of longdistance binding in North American Icelandic. In: Page BR and Putnam M (eds) Moribund Germanic Heritage Languages in North America: Theoretical perspectives and empirical findings. Leiden/Boston: Brill, pp. 203-223.

$\mathrm{R}$ Development Core Team (2018) R: A language and environment for statistical computing. Vienna: $\mathrm{R}$ Foundation for Statistical Computing. Available at: http://www.R-project.org/ (accessed April 2018).

Rayner K (1998) Eye movements in reading and information processing: 20 years of research. Psychological Bulletin 85: 618-660.

Reuland E (2006) Binding Theory: Terms and Concepts. In: Everaert M and van Riemsdijk H (eds) Blackwell Companion to Syntax. Malden, MA: Blackwell, Chapter 9.

Ronai E (2017) Quantifier scope in heritage bilinguals: a comparative experimental study. Poster presented at NELS 2017. University of Iceland, October 27-29.

Ross S (1998) Self-assessment in second language testing: A meta-analysis and analysis of experiential factors. Language Testing 5: 1-20.

Rothman J (2007) Heritage speaker competence differences, language change and input type: inflected infinitives in Heritage Brazilian Portuguese. International Journal of Bilingualism 11(4): 359-389.

Rothman J (2009) Understanding the nature and outcomes of early bilingualism: Romance languages as heritage languages. International Journal of Bilingualism 13(2): 155163.

Rothman J and Treffers-Daller J (2014) A prolegomenon to the construct of the native speaker: heritage speaker bilinguals are natives too! Applied Linguistics 35: 93-98. doi: 10.1093/applin/amt049.

Rudnev P (2008) Some syntax and semantics of long-distance reflexives in Turkish and elsewhere. [Unpublished manuscript].

Ruigendijk E, Friedmann N, Novogrodsky, R and Balaban N (2010) Symmetry in comprehension and production of pronouns: A comparison of German and Hebrew. Lingua 120: 1991-2005. 
Schmid MS and Köpke B (2007) Bilingualism and attrition. In: Köpke B, Schmid MS, Keijzer $\mathrm{M}$ and Dostert S (eds), Language attrition: Theoretical perspectives. Amsterdam/Philadelphia: John Benjamins, pp. 1-8.

Schneider W, Eschman A and Zuccolotto A (2002a) E-Prime user's guide. Pittsburgh, PA: Psychology Software Tools, Inc.

Schneider W, Eschman A and Zuccolotto A (2002b) E-Prime reference guide. Pittsburgh, PA: Psychology Software Tools, Inc.

Scontras G, Fuchs Z and Polinsky M (2015) Heritage language and linguistic theory. Frontiers in Psychology 6: 1545. doi: 10.3389/fpsyg.2015.01545

Scontras G, Polinsky M, Tsai C-YE and Mai K (2017) Cross-linguistic scope ambiguity: When two systems meet. Glossa: a journal of general linguistics 2(1): 36. DOI: http://doi.org/10.5334/gjgl.198

Sezer E (1980) On reflexivization in Turkish. In: Ševčenko I and Sysyn FE (eds) Harvard Ukrainian Studies Eucharisterion: Essays presented to Omeljan Pritsak on his Sixtieth Birthday by his Colleagues and Students Vol. 3/4. Cambridge,MA: Ukrainian Research Institute, Harvard University, pp. 748-759.

Sezer E (1991) Topics in Turkish syntax. PhD Thesis, Harvard University.

Sorace A (2004) Native language attrition and developmental instability at the syntaxdiscourse interface: Data, interpretations and methods. Bilingualism: Language and Cognition 7(2): 143-145.

Sprouse RA (2011) The Interface Hypothesis and Full Transfer/Full Access/Full Parse: A brief comparison. Linguistic Approaches to Bilingualism 1: 97-100.

Sturt P (2003) The time-course of the application of binding constraints in reference resolution. Journal of Memory and Language 48: 542-562.

Tsai E, Scontras G, Mai K and Polinsky M (2014) Prohibiting Inverse Scope: An Experimental Study of Chinese vs: English. Empirical Issues in Syntax and Semantics 10: 1-18.

Underhill R (1976) Turkish grammar. Cambridge, MA: MIT Press.

Vasishth S and Drenhaus H (2011) Locality in German. Dialogue \& Discourse 2(1): 5982 .

Von der Malsburg T and Angele B (2016) False positives and other statistical errors in standard analyses of eye movements in reading. Journal of Memory and Language 94: 119-133.

Wagers MW and Phillips C (2014) Going the distance: Memory and decision making in active dependency construction. Quarterly Journal of Experimental Psychology 67: 1274-1304.

Yakut AB (2015) The logophoric behavior of the strict local anaphor kendi 'self' in Turkish. In: Joseph A and Predolac E (eds) Proceedings of the 9th workshop on Altaic formal linguistics, MIT Working Papers in Linguistics \#76. Cambridge, MA: MITWPL.

Zemskaja EA (ed) (2001) Jazyk russkogo zarubež'ja (The language of the Russian diaspora). Moscow/Vienna: Wiener Slawistischer Almanach. 